\title{
Bionomy and Behorvior \\ Electrophysiologic and behavioral responses mediated by volatiles involved in the repellency of Apis mellifera (Lepeletier) (Hymenoptera: Apidae)
}

\author{
Patricia Daniela da Silva Pires ${ }^{\bowtie(0)}$, Josué Sant'Ana ${ }^{\circledR}$ Ricardo Bisotto-de-Oliveira
}

Universidade Federal do Rio Grande do Sul, Faculdade de Agronomia, Departamento de Fitossanidade.

\author{
EntomoBrasilis 13: e903(2020)
}

\begin{abstract}
Edited by:
William Costa Rodrigues

Article History:

Received: 25.iii.2020

Accepted: 07.vi.2020

Published: 20.vii.2020

$\bowtie$ Corresponding author:

Patricia Daniela da Silva Pires

乃 patidpires@gmail.com

Funding agencies:

$\Delta$ Coordenação de Aperfeiçoamento de Pessoal de Nível Superior (CAPES); Conselho Nacional de Desenvolvimento Científico e Tecnológico (CNPq)
\end{abstract}

\begin{abstract}
Repellent volatiles to insects might be an important tool for management of bees in areas which the presence of these organisms is not required. This study aimed to evaluate the electroantennal and behavioral responses of Africanized honeybees (workers), Apis mellifera (Lepeletier) (Hymenoptera Apidae), at different ages, to benzaldehyde (BA) and methyl anthranilate (MA) and to evaluate the potential repellency of these compounds under field conditions. Laboratory tests were conducted to study electroantennographic responses $(\mathrm{mV})$ and chemotactic behavior of worker bees aged 1-5 (young) and 20-30 (old) days in four choice olfactometer. Electrophysiological responses to each compound did not differ between young and old workers. Bees antennae (young) triggered significantly greater responses to BA, in the older ones, a higher response was observed to MA, both compared to control (ethanol). The threshold response to BA and MA was achieved at $10 \mu \mathrm{g} / \mu \mathrm{L}$, both compounds repelled bees at the same dose in olfactometer. Treatments with BA and MA, in field conditions, were less visited by scouter honey bees than those without these compounds (control).
\end{abstract}

Keywords: Benzaldehyde; chemical communication; metyl antranilate; repellents.
T he Africanized honey bee (AHB) had its origin through a natural crossing of Apis mellifera scutellata Lepeletier (Hymenoptera, Apidae) (African honeybee) and Apis mellifera ligustica Spinola (Hymenoptera, Apidae) (European honeybee) (MICHENER, 1975). These bees use flower volatiles for guidance during foraging. They are composed of a complex mixture of chemical products, such as those belonging to the groups of terpenes, alcohols, aldehydes, ketones and esters (KNUDSEN et al. 2006). Some plant metabolites may also act as a mechanism of physiological defense, as shown to methyl anthranilate (MA) (PAGARE et al. 2015). This ester is released by plants damaged by herbivorous (HUOT et al. 2014; PAGARE et al. 2015), it repels some insects (PANkIw 2009; Mural et al. 2000) and birds (PANKIW 2009) and is also attractive to some predators and parasitoids (Mural et al. 2000). Benzaldehyde is another secondary plant volatile, found in bay essential oil (Laurus nobilis L.- Lauraceae) and bitter almond oil (Amygdalus communis Ludwig - Rosaceae), among other plants (AzAmBujA 2020). This compound is an effective insect repellent (PAULRA et al. 2011), including bees of European and Africanized races (Collins et al. 1996).

The use of repellent substances can be an important tool for AHB management in rural areas in which the presence of these organisms is not required, e.g., bees can infest vineyards during grape's ripening, damaging fruits (HICKEL \& Schuck 1995). In passion fruit crops, bees are able to remove the pollen, but they are too small for pollination, it might also impact fruit production (FANCELLI \& Mesquita 1998). Thus, this study aimed to evaluate the electrophysiological and behavioral responses of Africanized honeybees (workers), A. mellifera, at different ages, to methyl anthranilate and benzaldehyde, as well as, to observe the potential repellency of these compounds under field conditions.

\section{MATERIAL AND METHODS}

The AHB workers were isolated from different hives with mature honeycomb and divided into two age groups, 1-5 days (young/nursing) and/or 20-30 days (old/foragers). First, the honeycombs were removed from the beehives and kept in a climate-controlled chamber until the emergence of adult bees. For age control, bees were marked on the thorax with daily changing colours (Uniposca ${ }^{\circledR}$ pen), following emergence, and were released back into the origin hive, where they remained until the assays. One hour before the test, the hive was handled with a bee smoker and the marked worker bees were captured and transferred, with a modified portable vacuum cleaner (Makita, mod. Cl100 Dw), to plastic cups $(200 \mathrm{ml})$ with distilled water, offered in cotton balls.

Electroantennography (EAG). The honeybees were immobilized and observed with a stereo microscope (400 $X$ amplification) where sectioning of the right antenna was performed. The antennae were attached to a two-filament silver electrode using conductive gel (Spectra 360, Electrode Gel-Parker). The antennae were subjected to air pulses generated by a flow controller (CS -02, Syntech ${ }_{\circledast}$ ) in 
a volume of $2.5 \mathrm{~mL} / 0.5 \mathrm{~s}$ with different treatments. It has been stipulated time of one minute between successive stimuli so that the antenna regained their capacity to perceive odorant. Analogical signal responses, measured in $\mathrm{mV}$, were captured, amplified and processed with a data acquisition controller (IDAC -4 Syntech $\left.{ }_{\circledast}\right)$ and subsequently recorded by software (EAG2000, Syntech).

For the sensitivity test (dose-response), we used five doses from $10^{-2}$ to $10^{2} \mu \mathrm{g} / \mu \mathrm{L}$, solutions in ethanol (Sigma-Aldrich) of benzaldehyde (99\%; Sigma-Aldrich) and methyl anthranilate (MA) (98\%; Sigma-Aldrich), as well as, pure substances. The treatments were applied $(10 \mu \mathrm{L})$ individually on filter paper $(1.5 \times 2.5 \mathrm{~cm})\left(\right.$ Whatman, $\left.4 \times 15 \mathrm{~cm} / 80 \mathrm{~g} / \mathrm{m}^{2}\right)$ and then placed into a Pasteur pipette. The selectivity of young and/or old bees was recorded using $10 \mu \mathrm{L}$ of BA or MA (both at $10 \mu \mathrm{g} /$ $\mu \mathrm{L}$ ) with an automatic pipette (Confort ${ }^{\circledR}$ Discovery).

The stimuli order display to the antenna was pseudo-random procedure, except for the control (ethanol - $10 \mu \mathrm{L}$ ), which was always used at the beginning and the end of each bioassay. We performed 18 replicates/treatment. The antennae were used only once in each repetition.

Chemotactic behavioral assays. Chemotactic behavioral bioassays were conducted to test the responses of young (1-5) and/or old (20-30 days) A. mellifera workers to BA and MA in a four-arm olfactometer $(22 \mathrm{~cm}$ in length and $1.5 \mathrm{~cm}$ internal diameter). Charcoal-filtered and humidified air was pushed into the system at $0.3 \mathrm{~L} / \mathrm{min}$ and pulled out at $0.4 \mathrm{~L} /$ min, therefore it was allowed to form a gradient flow inside of the olfactometer. This "push-pull" system prevents entry of contaminating volatiles from the exterior. The tests were conducted with controlled conditions $\left(25 \pm 1{ }^{\circ} \mathrm{C}\right.$ and $70 \pm 10 \%$ $\mathrm{RH}$ ) and in the light (900 lumens).

Three of the olfactometer arms received the same treatment benzaldehyde or methyl anthranilate $(10 \mu \mathrm{L}-10 \mu \mathrm{g} / \mu \mathrm{L})$ and the fourth arm was connected to a syringe containing filter paper treated with $10 \mu \mathrm{L}$ of ethanol (control). After every four replicates, the odor source was replaced and after every eight. At this time the olfactometer was exchanged and cleaned with detergent, distilled water, and acetone. Silicone tubing, filter papers, and glass syringes were baked in an oven for at least $12 \mathrm{~h}$ at $45^{\circ} \mathrm{C}$ prior to use and the treatment arms were rotated. The bees were released at the center of the olfactometer and the residence time (measured as the mean of total bioassay time spent in each arm of the olfactometer), was quantified when the insect moved $2.0 \mathrm{~cm}$ into one of the four arms of the olfactometer. Each individual was sampled only once. Each assay lasted $5 \mathrm{~min}$ and was replicated 40 times. The insects that remained in the central area were considered non-responsive and they were not considered in the statistical analysis.

Field assay. Tests were performed in Porto Alegre, RS, Brazil from October to December, on days with temperature between 20 and $30^{\circ} \mathrm{C}$, without rainfall.

In each test we used $2 \mathrm{ml}$ of pure BA or MA, pipetted onto filter paper disks $\left(10 \mathrm{~cm} \varnothing\right.$; Whatman, $\left.80 \mathrm{~g} / \mathrm{m}^{2}\right)$. The disks were placed on Petri dishes $(13 \mathrm{~cm} \varnothing)$, and a feeder containing 40 $\mathrm{mL}$ of honey solution (25\%) was added to the central portion of each dish. The assembly (Petri dishes, filter paper with treatment and feeder) was fixed on a stake and positioned $80 \mathrm{~cm}$ above the ground and distanced, approximately, 10 $\mathrm{m}$ from colonies of $A$. mellifera and $2 \mathrm{~m}$ each other, forming a triangle. As a control, we used a dish containing only a filter paper disk (no compounds) and a feeder with the honey solution. We performed one repetition every day with each substance, totaling 30 replicates. The experiment was conducted between 10:00 and 12:00 h and lasted for $30 \mathrm{~min}$ for each substance. The bees that fed during the visits were counted and marked with non-toxic ink (UniPOSCA ${ }^{\circledR}$ pen), with different colors for each treatment.

Statistical analysis. The electrophysiological responses of each treatment were recorded in $\mathrm{mV}$ and the EAG average responses were compared by Kruskal-Wallis (Dunn test; $\alpha=0.05$ ). The residence time in the olfactometer bioassays was evaluated with Friedman test and the mean number of honeybees who visited the treatments was compared by ANOVA (Tukey test; $a=0.05$ ) with Bioestat $5.3 \AA$ software (AYRES, 2007) $(P<0.05)$.

\section{RESULTS}

Electroantennography. The threshold response to concentrations obtained from electroantennographic bioassays (EAG) to BA ( $<<0.0001$, gl: 6$)$ (Figure 1$)$ and MA (P $=0.0043$, gl: 6) (Figure 2) was achieved at $10 \mu \mathrm{g} / \mu \mathrm{L}$ (KruskalWallis). Concentrations below these values were similar to the control (ethanol) $(\mathrm{P}>0.05)$.

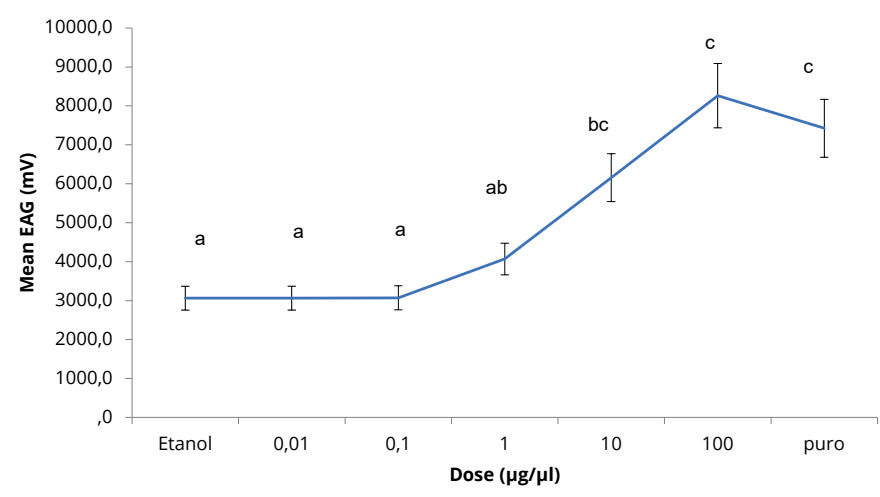

Figure 1. Electrophysiological responses ( \pm SEM) of Apis mellifera (20-30 days old) at six concentrations of benzaldehyde and the solvent ethanol (control). *Means followed by different letters are statistically different (Kruskal-Wallis, $P<0.05)(n=18)$.

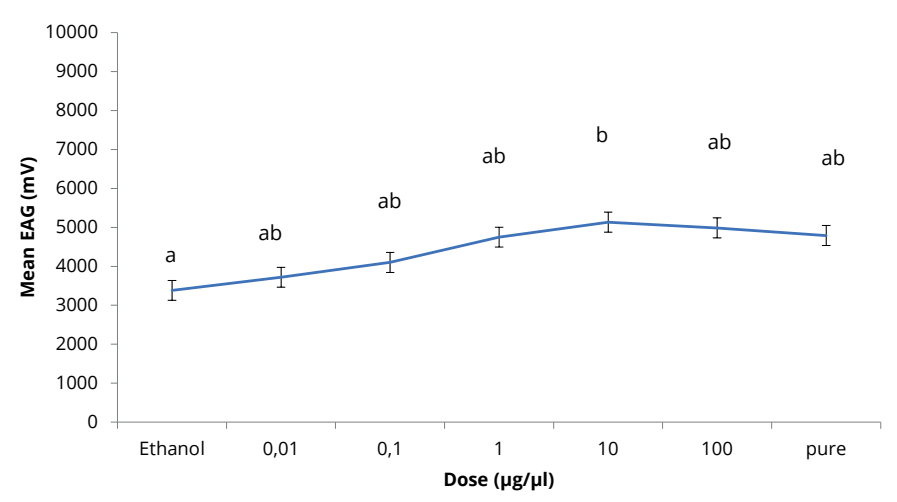

Figure 2. Electrophysiological responses ( \pm SEM) of Apis mellifera (20-30 days old) at six concentrations of methyl anthranilate: and the solvent ethanol (control). *Means followed by different letters are statistically different (Kruskal-Wallis, $P<0.05)(n=18)$.

Electrophysiological responses of $A$. mellifera to each compound (selectivity) did not differ between young and old worker bees (Tukey, P > 0.05). Bee's antennae between one and five days old triggered significantly greater responses to BA treatment compared to control (ANOVA, $P<0.01$ ). In the older ones, a higher response was also observed for MA, when compared to ethanol (ANOVA, P < 0.0001) (Table 1).

Chemotactic behavioral assays. We observed, for both for young and old bees, a longer residence time in the arm of the olfactometer that contained the control treatment than 
in the other three arena's arms, containing both $\mathrm{MA}(\mathrm{P}=$ $0.0008)$ and $B A(P<0.0001)$ (Figure 3$)$.

Field assay. Both, MA and BA, were repellent to bees. The average number of visitors at the feeder containing the honey solution in the presence of MA was $1.37 \pm 1.06$, and at its control, $9.3 \pm 2.59$ (Tukey; $\mathrm{P}<0.001$ ). In the BA treatment, the number of bees observed was $1.17 \pm 1.21$ and, in control, $7.13 \pm 2.3$ (Tukey; $P<0.0001$ ).

Table 1. Electrophysiological responses \pm SEM $(\mathrm{mV})$ of bees in two age groups (1-5, and 20-30 days) with benzaldehyde (BA), methyl anthranilate (MA) and ethanol (control) $(n=18)$.

\begin{tabular}{lcc}
\hline \multirow{2}{*}{ Treatment } & \multicolumn{2}{c}{ Workers age (days) (response (mV $\mathbf{m}$ SEM) } \\
\cline { 2 - 3 } & $\mathbf{1 - 5}$ & $\mathbf{2 0 - 3 0}$ \\
\hline BA & $10.12 \pm 1.20 \mathrm{Aa}$ & $9.90 \pm 0.90 \mathrm{Aa}$ \\
MA & $8.65 \pm 1.25 \mathrm{ABa}$ & $6.98 \pm 0.70 \mathrm{Ba}$ \\
Ethanol (control) & $6.07 \pm 0.56 \mathrm{Ba}$ & $4.12 \pm 0.51 \mathrm{Ca}$ \\
\hline
\end{tabular}

* Means followed by different capital letters in columns and lowercase letters, lines, differ by ANOVA $(P<0.05)$.

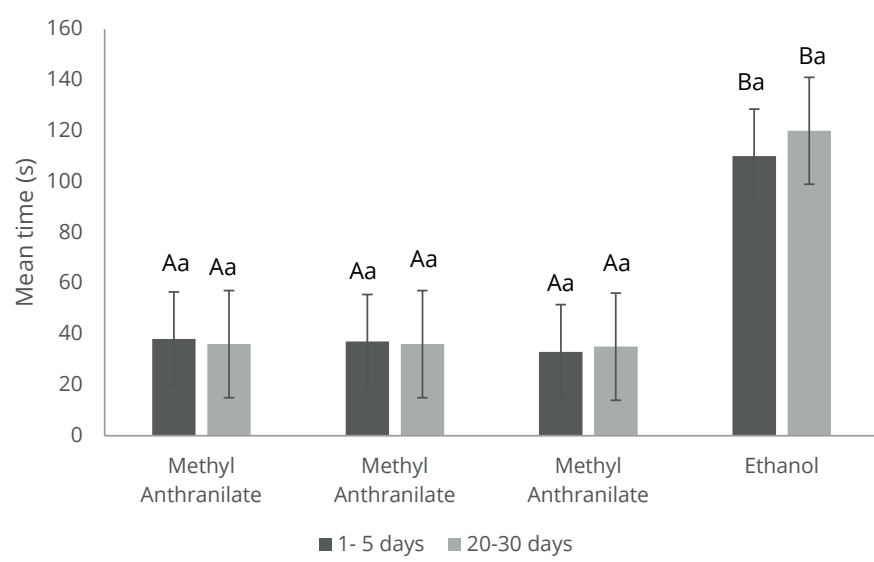

Figure 3. Residence time ( $\pm \mathrm{SE}$ ) of worker Apis mellifera 1-5 and 20-30 days old in four arms olfactometer containing ethanol and benzaldehyde or methyl anthranilate $(10 \mu \mathrm{g} / \mu \mathrm{L})$. Columns of the same color followed by different capital letters and, from different colors (within each treatment), followed by minuscule letters, differs by Friedman test $(a=0.05)$. Observing time: 5 min.

\section{DISCUSSION}

We noticed that benzaldehyde and methyl anthranilate triggered, comparing to control, greater electrophysiological responses. The perception of these odors is probably related to the presence of GOBPs (General Odor Bind Proteins) receptor proteins associated with these substances in the sensilla of $A$. mellifera, which act as chemical signals, filtering only the compounds physiologically important to the insect (Pelosi et al. 2018). Frasnelli \& Vallortigara (2017) had already observed that olfactory sensilla of $A$. mellifera have the ability to respond to various odors, with cells more sensitive to some types of compounds than to others, thus the intensity of response depends on its importance on the insect's life cycle. In A. mellifera workers respond and memorize odors of interest and can recognize key substances from a range of volatiles, which may be pointing, for example, to food sources (SANDOZ 2011).

Plants release volatiles that attract nectarivorous and/or pollinivorous insects, such as bees, which pollinate them while feeding themselves (BURKLE \& RUNYON 2016). Therefore, we suggest that these odors (BA and MA), in low concentrations and/or in mixtures with other substances present in the flowers, can act in positive chemotropism with these insects in the field, helping them to locate pollen and/or nectar.
The type of behavioral response triggered by the insect to certain odor may also be linked to endogenous factors such as age and reproductive status (GADENNE et al. 2016). In this study, however, no differences were observed in the size of the responses to the same odor by young and old bees. In this sense, the bees of different age ranges can be equally sensitive to the main substances related to the resources in the vicinity of the hive. We observed that older bees were more selective to odors, i.e., they were more responsive to BA than to MA. Benzaldehyde is present in the composition of the scents of flowers from species such as Passiflora sp. (Passifloraceae), Pyrus malus L. (Rosaceae) and others (Reinhard et al. 2010). These plants are visited by A. mellifera during the flowering stage; therefore, benzaldehyde is considered to be a volatile important for the guidance of forager bees (KLAT et al. 2013).

In bioassays with BA and MA at a concentration of $10 \mu \mathrm{g} / \mathrm{L}$ (laboratory) or even in pure forms (field), we found that the bees were repelled. Thus, we assume that MA and BA can act in repellency of bees. However, we also should consider that a new odor exposed to bees may create a conflict in the olfactory memory triggering a temporary repellent behavior (Abramson et al. 2006).

Benzaldehyde was also reported as a repellent for Drosophila melanogaster Meigen (Diptera: Drosophilidae) (VERSCHUT et al. 2019) and A. mellifera (TowNSEND 1963), corroborating the data obtained in this study. According to TownSEND (1963), benzaldehyde (75\%) and methyl benzoate (50\%) triggered a percentage of repellency in European bees of $85 \%$ and $81 \%$, respectively. FreE et al. (1989) also found that another compound from the benzyl group (benzyl acetate), when applied in liquid paraffin at concentrations of 0.5 and 5 $\mathrm{mg} / 100 \mu \mathrm{L}$, repelled $A$. mellifera away from sunflower plants, Heliantus annuus L. (Asteraceae).

As in this study, the negative chemotropism triggered by MA had also been recorded for bees and wasps. PANKIW (2009), when performing tests to evaluate the defense potential of A. mellifera colonies, found that methyl anthranilate (10\%), when applied to the apiarist's clothes, reduced the number of attacks by $94 \%$ when compared to the control treatment. The author also observed a reduction in the number of nests built by the wasp Polistes sp. (Hymenoptera: Vespidae) in the presence of this substance.

Compounds from the anthranilate group (ethyl anthranilate, butyl anthranilate and dimethyl anthranilate) have also been described as repellents of D. melanogaster (KAIN et al. 2013) and Aedes aegypti L. (Diptera: Culicidae) (AfIFY et al. 2014). Contrary to what was observed in A. mellifera, Mural et al. (2000) observed that MA was attractive for Thrips hawaiiensis Morgan (Thysanoptera: Thripidae) and Thrips coloratus Schmutz, as well as for the Ceranisus menes Walker parasitoid (Hymenoptera: Eulophidae).

Further studies on the chemotactic action of methyl anthranilate and benzaldehyde on $A$. mellifera, especially regarding the concentrations and formulations to be used, can result in an important tool for management of bees in areas in which the presence of these organisms (individuals and/or swarming) are not wanted, such as in Vitis vinifera L. (Vitaceae) orchards during harvest time. It is important to point out that the use of these compounds depends on more detailed studies on their interactions, especially with the insect fauna present in the environment.

The electroantennographic response threshold of Africanized A. mellifera for methyl anthranilate and benzaldehyde was 10 $\mu \mathrm{g} / \mu \mathrm{L}$, bees aged 1 to 5 days and 20 to 30 days perceive the odors equally; MA and BA trigger a repellency behavior on $A$. 
mellifera in olfactometry and, when pure, in the field.

\section{ACKNOWLEDGEMENTS}

This work received financial support from the Coordenação de Aperfeiçoamento de Pessoal de Nível Superior (CAPES); the Conselho Nacional de Desenvolvimento Científico e Tecnológico (CNPq 303758/2018-0) for the financial support and for fellowships awarded (CNPq 306474/2015-8).

\section{REFERENCES}

Abramson, Cl, MK Wilson, JB Singleton, PA Wanderley, MJA Wanderley \& LM Michaluk, 2006. Citronella is not a repellent to africanized honey bees Apis mellifera L. (Hymenoptera: Apidae). Bioassay, 1: 1-7. DOI: https://doi.org/10.14295/BA.v1.0.40

Afify, A, B Horlacher, J Roller \& CG Galizia, 2014. Different repellents for Aedes aegypti against blood-feeding and oviposition. PLoS One, 9: 1-8. DOI: https://doi.org/10.1371/ journal.pone. 0103765

Ayres, M, MJr Ayres, DL Ayres \& AAS Santos, 2007. BioEstat 5.0 Aplicações estatísticas nas áreas das ciências biológicas e médicas. Belém, Mamiraua.

Azambuja, W, 2020. Benzaldeído ou aldeído benzóico Available on: <http://www.oleosessenciais.org/benzaldeido-oualdeido-benzoico>. [Accessed in: 25.ii.2020].

Burkle, LA \& JB Runyon, 2016. Drought and leaf herbivory influence floral volatiles and pollinator attraction. Global Change Biology, 22:1644-1656. DOI: https://doi.org/10.1111/gcb.13149

Collins, AM, WL Rubink, JIC Aguilar \& RL Hellmich II, 1996. Use of insect repellents for dispersing defending honey bees (Hymenoptera: Apidae). Journal of Economic Entomology, 89: 608-613. DOI: https://doi.org/10.1093/jee/89.3.608

Fancelli, M \& ALM Mesquita, 1998. Pragas do maracujazeiro. In. Braga Sobrinho, R, JE Cardoso, FCO Freire (Eds). Pragas de fruteiras tropicais de importância agroindustrial. EMBRAPA.

Frasnelli, E \& G Vallortigara, 2017. Distribution of antennal olfactory and non-olfactory sensilla in different species of bees. Symmetry, 9:1-10. DOI: http://doi.org/10.3390/ sym9080135

Free, JB \& AW Ferguson \& JR Simpkins, 1989. Honeybee responses to chemical components from the worker sting apparatus mandibular glands in field tests. Journal of Apicultural Research, 28: 7-21. DOI: https://doi.org/10.10 80/00218839.1989.11100814

Gadenne, C, RB Barrozo \& S Anton, 2016. Plasticity in Insect Olfation: To smell or not to smell? Annual Review of Entomology, 61: 317-33. DOI: https://doi.org/10.1146/ annurev-ento-010715-023523

Hickel, ER \& E Schuck, 1995. Vespas e abelhas atacando a uva no Alto do Vale do Rio do Peixe, o que fazer e quando insetos benéficos passam a ser pragas. Agropecuária Catarinense, 8: 38-40.

Huot, B, J Yao, BL Montgomery \& SY He, 2014. GrowthDefense Tradeoffs in Plants: A Balancing Act to

\section{Suggestion citation:}

Pires, PDS, J Sant'Ana \& R Bisotto-de-Oliveira, 2020. Electrophysiologic and behavioral responses mediated by volatiles involved in the repellency of Africanized bees Apis mellifera (Lepeletier) (Hymenoptera: Apidae). EntomoBrasilis, 13: e903.

Available in: doi: 10.12741/ebrasilis.v13.e903
Optimize Fitness. Molecular Plant, 7: 1267-1287. DOI: https://doi.org/10.1093/mp/ssu049

Kain, P, SM Boyle, SK Tharadra, T Pham, A Dahanukar \& A Ray, 2013. Odour receptors and neurons for DEET and new insect repellents. Nature, 502: 507-514. DOI: https://doi.org/10.1038/nature12594

Klatt, BJ, C Burmeister, C Westphal, T Tscharntke \& M von Fragstein, 2013. Flower volatiles, Crop varieties and bee responses. PLoS One, 8: e72724. DOI: https://doi.org/10.1371/journal.pone.0072724

Knudsen, JT, R Eriksson, J Gershenzon \& B Stahl, 2006. Diversity and distribution of floral scent. The botanical Review, 72: 1-120. DOI: https://doi.org/10.1663/00068101(2006)72[1:DADOFS]2.0.CO;2

Michener, CD, 1975. The Brazilian bee problem. Annual Review Entomology, 20: 399-416. DOI: https://doi.org/10.1146/ annurev.en.20.010175.002151

Murai, T, T Imai \& M Maekawa, 2000. Methyl anthranilate as an attractant for two thrips species and the thrips parasitoid Ceranisus menes. Journal of Chemical Ecology, 26: 25572565. DOI: https://doi.org/10.1023/A:1005536713025

Pagare, S, M Bhatia, N Tripathi, S Pagare \& YK Bansal, 2015. Secondary metabolites of plants and their role: overview. Current Trends in Biotechnology and Pharmacy, 9: 293304.

Pankiw, T, 2009. Reducing honey bee defensive responses and social wasp colonization with methyl anthranilate. Journal of Medical Entomology, 46: 782-788. DOI: https://doi.org/10.1603/033.046.0408

Paulraj, MG, AD Reegan \& S Ignacimuthu, 2011. Toxicity of Benzaldehyde and Propionic Acid against Immature and Adult stages of Aedes aegypti (Linn.) and Culex quinquefasciatus (Say) (Diptera: Culicidae). Journal of Entomology, 8: 539-547. DOI: https://doi.org/10.3923/ je.2011.539.547

Pelosi, P, J Zhu \& W Knoll, 2018. Odorant-Binding Proteins as Sensing Elements for Odour Monitoring. Sensors, 3248: 1-19. DOI: https://doi.org/10.3390/s18103248

Reinhard, J, M Sinclair, M Srinivasan \& C Claudianos, 2010. Honeybees learn odour mixtures via a selection of key odorants. PLoS ONE, 5: 1-14. DOI: https://doi.org/10.1371/ journal.pone.0009110

Sandoz, JC, 2011. Behavioral and neurophysiological study of olfactory perception and learning in honeybees. Frontiers in Systems Neuroscience, 5:1-20. DOI: https://doi.org/10.3389/fnsys.2011.00098

Townsend, GF, 1963. Benzaldehyde: a new repellent for driving bees. Bee World, 44: 146- 149. DOI: https://doi.org/10.1080/0005772X.1963.11097015

Verschut, TA, MA Carlsson \& PA Hambäck, 2019. Scaling the interactive effects of attractive and repellent odours for insect search behavior. Scientific Reports, 9. DOI: https://doi.org/10.1038/s41598-019-51834-1

$\star * * * * * * * * *$
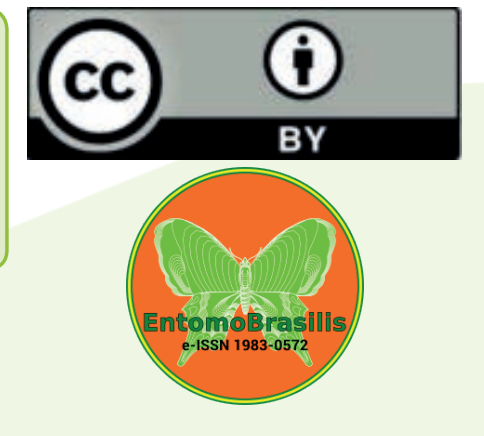

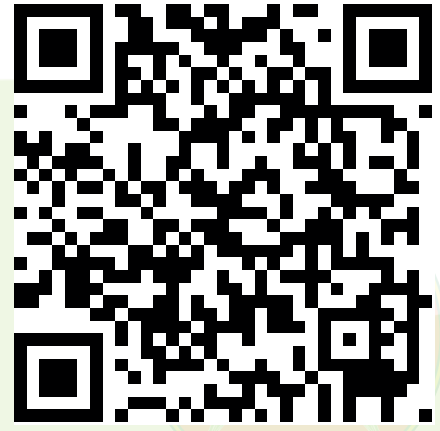

